\title{
Development of Three Dimensional Landslide Prediction System Based on GIS
}

\author{
Masahiko Kadonoki ${ }^{1)}$ Yasuhiro Yamada ${ }^{2)}$ Isamu Hirano ${ }^{3)}$ Toshifumi Matsuoka ${ }^{4)}$ \\ 1) Master student, Dept of geological Engineering, University of Kyoto \\ 2) Research Associate, Dept of geological Engineering, University of Kyoto \\ 3) Associate Professor, Dept of geological Engineering, University of Kyoto
}

4) Professor, Dept of geological Engineering, University of Kyoto

\begin{abstract}
Predicting landslides is a very important theme in Japan, because of its mountainious topography and geologically active location. In order to predict landslides, it is necessary to simultaneously consider many kinds of information (geology, topology, and groundwater etc.). Geographical Information Systems (GIS) can be a very important tool for landslide prediction. In this study, we attempted to develop a landslide prediction system and made a landslide hazard map at a survey area in Toyama prefecture by using GIS.
\end{abstract}

\section{Introduction}

In Japan, there are about 150 cases of landslides every year because of its mountainious topography and geologically active location. In addition, the population density of Japan is very high, so the damage from landslides can be very serious. Using conventional landslide prediction methods, it is not possible to calculate the safety factor in a large area because it is necessary to consider many kinds of information (geology, topology, and groundwater etc.) simultaneously which is very difficult.

Recently, Geographic Information System (GIS) are developing as a remarkable tool to manage and control many different kinds of information at once. Using GIS, it may be possible to incorporate many layers of information that have an influence on landslides, and develop a new landslide prediction system that can calculate the safety factor in a large area.

In this study, we first tried to calculate safety factor with only topographic information. Next, we incorporated information about resistivity from a helicopter-borne electromagnetic survey with topographic information, and we calculated safety factor again employing both information.

\section{Geographic information systems (GIS)}

Geographic information systems (GIS) is a computer-based information system which can handle the spatial information and the attribute information related to various geographical phenomenon (Longley et al., 2001). It manages these together, equiped with basic functions of data input, management, analysis and presentation.

The purpose of the data analysis by GIS is to search for a characteristic or a pattern from a large data volume related to geographic feature, and to discuss their spatial relationships. To do this we can use many of modern computer functions, such as repeated calculations, high-speed access to a geographical database and visualization technique. In particular, computer graphics technology is able to convert spatial data into other forms and engineers can interpret and recognize them easily. For example, GIS provides distribution maps of geographical phenomenon with points, lines and 
polygons and statisticd graphs, and maps. There are four general functions of GIS used for spatial analysis, being: (1) Attribute searching, (2) Space searching, (3) Data generation, and (4) Data visualization (Fig.1). From this point of view, GIS can be considered as an interpretation or a decision-making system for spatial data related to geography. This is similar to the work station system for seismic data interpretation, which are widely used in the oil industry(Coburn and Yarus, 2000).

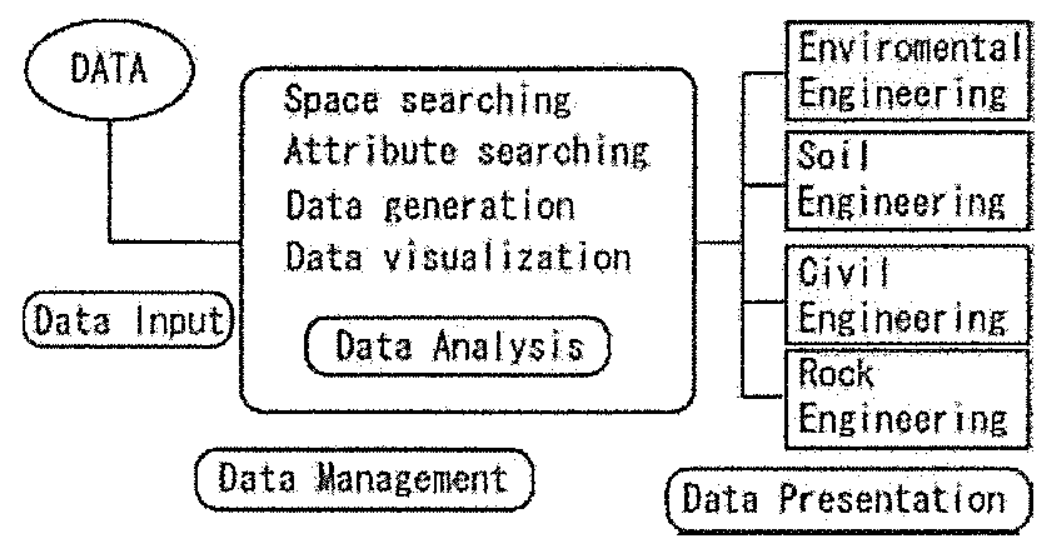

Fig. 1 Applications of GIS to Engineering fields

\section{Calculation of site safety factor}

To calculate the safety factor, we use the Hovland method. In this method, the mass subjected to landslide is divided with a square mesh. In many past landslides, the shape of sliding mass is ellipsoidal, and we also assume this form. To determine the most unstable sliding mass, the safety factor at many trial sliding surfaces must be calculated randomly. To accomplish this, we use Monte Carlo Simulation.

\subsection{Hovland method}

In the Hovland method, the safety factor $\left(F_{3 D}\right)$ can be calculated by:

$$
F_{3 D}=\frac{\sum_{j} \sum_{i}\left(\frac{C_{j i}}{\cos \left(\theta_{j i}\right)}-\left(\left(Z_{j i}-z_{j i}\right) \gamma^{\prime} \cos \left(\theta_{j i}\right) \cos \left(A s p_{j i}-A s p A v r\right)-u_{j i}\right) \tan \left(\Phi_{j i}\right)\right)}{\sum_{j} \sum_{i}\left(Z_{j i}-z_{j i}\right) \gamma^{\prime} \sin \left(\theta_{j i}\right) \cos \left(A s p_{j i}-A s p A v r\right)}
$$

Wher, $\mathrm{C}$ is viscosity $\left(\mathrm{kN} / \mathrm{m}^{2}\right), \mathrm{Z}$ is elevation of ground surface $(\mathrm{m}), \mathrm{z}$ is elevation of sliding surface $(m)$, AspAvr is average of dip azimuth $\left({ }^{\circ}\right)$, Asp is dip azimuth of each point $\left({ }^{\circ}\right)$, $u$ is pore pressure $\left(\mathrm{kN} / \mathrm{m}^{2}\right), \gamma^{\prime}$ is mass density $\left(\mathrm{kN} / \mathrm{m}^{3}\right), \theta_{j i}$ is slope angle $\left(^{\circ}\right)$, and $\phi_{j i}$ is angle of internal friction $\left({ }^{\circ}\right)$. By this equation, small values of safety factor area correlate with a high potential for landslide. 


\subsection{Monte Carlo Simulation}

Monte Carlo simulation employs random number, that have made by multiplicative congruetial method. We calculate the safety factor of many trial surface by randomly changing the center point and the mejor axis length and tilt of an ellipsoidal sliding mass. Fig.2 illustrates three trial iterations for such a simulation. Trial surface 3 is the most unstable in this illutration.

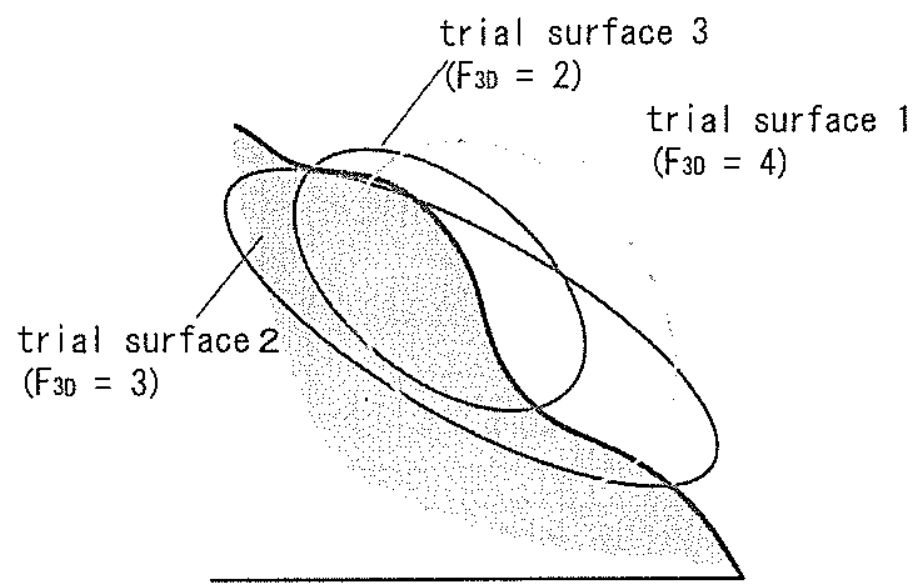

Fig. 2 Illustration of these trial Monte Carlo iterations for topographic instability.

\section{Helicopter-borne electromagnetic method (HEM)}

The AEM (Airbome electromagnetic method) was originally developed for fixed-wing aircraft to explore for ore deposits over a large area quickly. When a helicopter is used the method is called HEM (Helicopterborne Electro-Magnetic method). HEM has high resolving power at shallow depth since the helicopter can fly at lower height compared with a standard aircraft. We can summarize the features of HEM as follows (Konishi, 1998);

- HEM can investigate a large area at low cost.

- HEM can be employed in steep topography where the access is difficult.

- The influence of the topographic undulation is minimal, the homogeneous data are provided.

- Using multiple frequencies, the three-dimensional data acquisition and interpretation is possible and we can also obtain the distribution about resistance with areal and depth directions.

In this study, five different frequencies were acquired simultaneously using five sets of transmitter and receiver coils. The apparent resistivity at shallow depth is obtained from the higher frequency data and at depth by the lower frequency. The adopted frequencies are $138 \mathrm{kHz}, 28 \mathrm{kHz}$, $5.5 \mathrm{kHz}, 1.1 \mathrm{kHz}$, and $0.22 \mathrm{kHz}$. Table 1 shows the approximate depth of penetration achieved at each frequency when the subsurface resistivity is in the order of several $\Omega \mathrm{m}$. These penetration depths are sufficient for civil and environmental engineering investigation. In this survey, the flight level of the helicopter is kept about $30 \mathrm{~m}$, the line spacing is $50 \mathrm{~m}$, the number of profile lines is 54 , and total length of profile becomes $30 \mathrm{~km}$. The data volume is 33000 points, where each point has 5 different frequencies. 
Table 1 Penetration depth of each frequency

\begin{tabular}{|c|c|}
\hline$f(k H z)$ & $z(m)$ \\
\hline 138 & 7 \\
\hline 28 & 15 \\
\hline 5.5 & 30 \\
\hline 1.1 & 60 \\
\hline 0.22 & 100 \\
\hline
\end{tabular}

\section{Survey area - Maeyama district}

The HEM survey was conducted in the Maeyama district of Tonami County in Toyama Prefecture in order to evaluate the landslide hazard area. In this area a large-scale landslide had occurred following the Tensho earthquake of November 13, 1586 (M 7.6).

Presently, there is no indication of landslide potential in this district. However, intermittent safety investigation becomes necessary since there exist important lifelines and institutions such as an electric power station and a national highway at the foot of the slope (Fig.3).

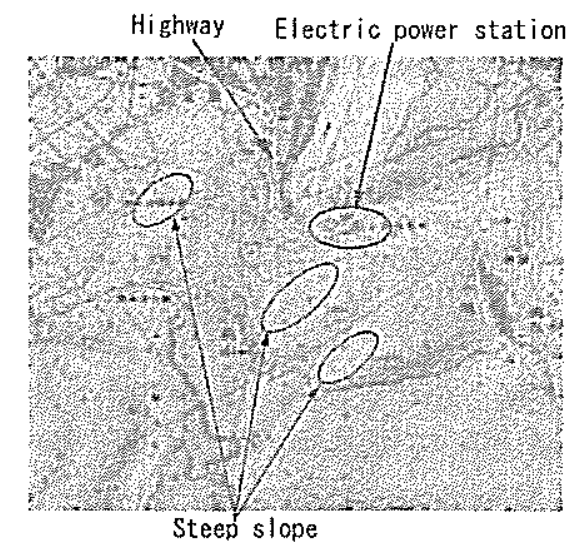

Fig. 3 Topographic map around the Macyama district

\section{Result}

\subsection{Result 1 - Safety factor with only topograpic information}

Fig.4 is a landslide hazard map which takes only topographic information into consideration. From this landslide hazard map, we can merely interpret that areas of steep slope have low safety factor values. But, as is well known, not only topographic information, but also many other kinds of information (groundwater, geology etc.) influence landslide potentially. So we have to survey these information. 


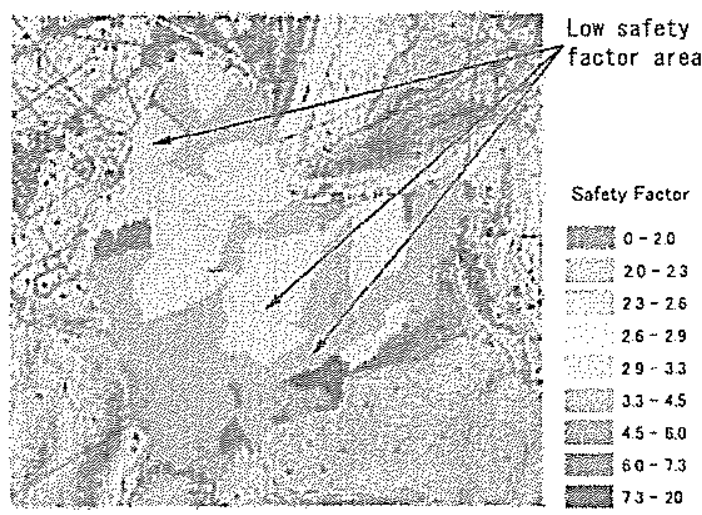

Fig. 4 Landslide hazard map based on only topographic information

\subsection{Result 2 - Apparent resistivity maps made by the HEM survey .}

Fresh rock does not conduct electricity, so its resistivity is high. However, in weakened and fractured rock allowing groundwater flow, resistivity is reduced. Thus, we can assume that low resistivity correlates with a weaker subsurface. Fig. 5 shows the results of the HEM survey.

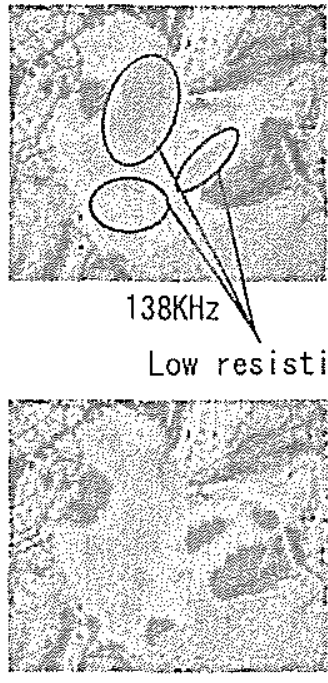

$1100 \mathrm{~Hz}$

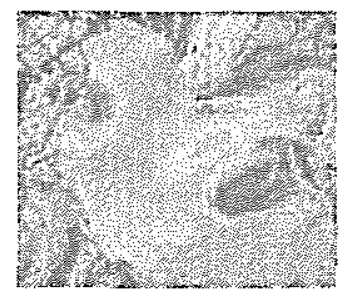

$28 \mathrm{KHz}$

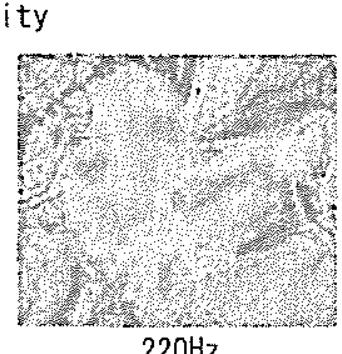

$220 \mathrm{~Hz}$

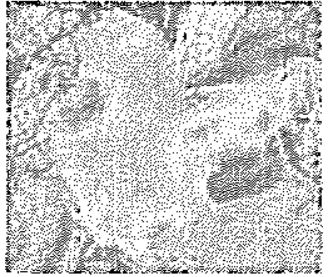

$5500 \mathrm{~Hz}$

Resistivity

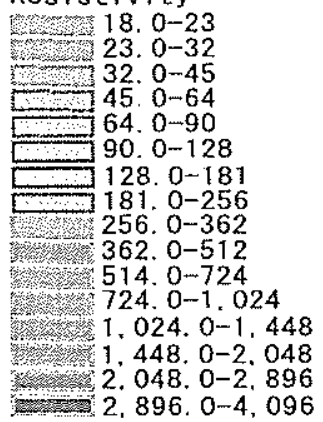

Fig. 5 Result of HEM survey 


\subsection{Result 3 - Safety factor employing both topographic and resistivity information}

After changing the physical properties that have an influence on landslide (angle of internal friction, viscosity etc.) at the low resistivity area, we recalculated safety factor. Fig.6-(a) is a remaked landslide hazard map. To justify this result, we compared this with the geological outcrop map. (Fig.6-(b)). The areas of low safety factor (calculated by GIS) correlate well with the areas where landslide have ever occured. However, areas of rockslide do not appear to show strong correlation with the calculated safety factor. This is because the large sliding mass retains its internal structure and physical properties remain unchanged.

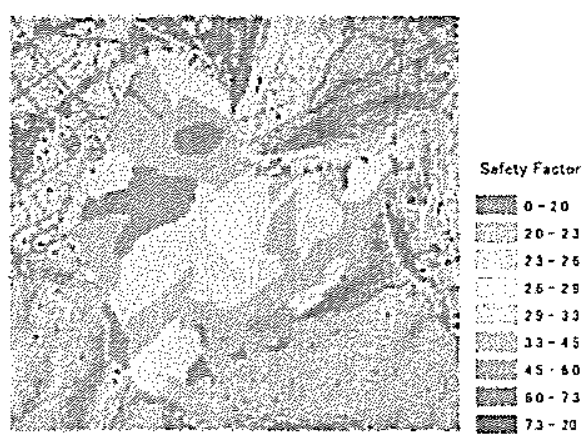

(a) Landslide hazard map

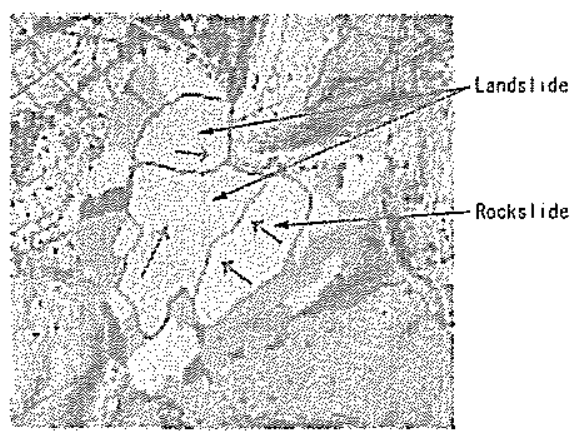

(b) Comparison with geological outcrop map

Fig. 6 Result of calculation and comparison with outcrop map

\section{Conclusions}

In this study, we made use of resistivity data from HEM survey in a GIS landslide hazard analysis. We could made a landslide hazard map which correlated well with outcrop map. These results indicate that the safety factor can be calculated with high accuracy over large areas rapidly and cost-efficiently.

\section{References}

Coburn T. C. and Yarus J. M. 2000, Geographic Information Systems in Petroleum Exploration and Devbelopment, AAPG Computer Application in Geology, No4, AAPG, Tulsa, 315

Konishi N. 1998, Three dimensional survey by helicopter-bome electromagnetic method, Buturitansa, 51, 643-658.

Longley P., Goodchild M. F., Maguire D. J. and Rhind D. W., 2001, Geographic Information Systems and Science, Wiely, New York, 454 